\title{
Chapter 19 \\ Reflections on Developing an Identity \\ for the Third Generation Nuclear Engineer in the Post-Fukushima Society
}

\author{
Robert Angelo Borrelli
}

\begin{abstract}
The March 2011 nuclear reactor accidents at the Fukushima, Japan nuclear reactor complex catalyzed public discussion about nuclear technology and energy worldwide. As part of this, in August 2011, the Department of Nuclear Engineering at the University of California-Berkeley (UCBNE) hosted the 2011 Advanced Summer School of Nuclear Engineering and Management with SocialScientific Literacy: Reflections on the Fukushima Nuclear Accident and Beyond (the Summer School). This unique program featured world leaders in nuclear engineering, social science, and history. The student body was comprised of post doctorate researchers and graduate students. This chapter will discuss the identity of the nuclear engineer within the context of the post-Fukushima society. Specifically, this is directed to what will be termed the 'third generation' engineer. In the upcoming decades, it is this third generation that will lead and shape perspectives on nuclear technology and develop new relationships with society. This chapter is intended to pose questions to the third generation to consider as part of their own, professional self-assessment. This chapter draws primarily from the experiences at the Summer School in an effort to direct meaningful discussions about the need to consider the identity of this third generation nuclear engineer in the post-Fukushima society.
\end{abstract}

Keywords Fukushima $\cdot$ Society $\cdot$ Engineering ethics $\cdot$ Nuclear energy $\cdot$ Historical inertia $\cdot$ Third generation

\footnotetext{
R.A. Borrelli $(\bowtie)$

Department of Nuclear Engineering, University of California, Berkeley,

Berkeley, CA 94720, USA

e-mail: r.angelo.borrelli@gmail.com
} 


\subsection{Preface}

The March 2011 nuclear reactor accidents at the Fukushima, Japan nuclear reactor complex triggered a scrutinous public discussion about nuclear technology on an unprecedented scale, much more so than from the accident at Chernobyl or Three Mile Island. As part of this, in early August 2011, the Department of Nuclear Engineering at the University of California-Berkeley (UCBNE) hosted the 2011 Advanced Summer School of Nuclear Engineering and Management with SocialScientific Literacy: Reflections on the Fukushima Nuclear Accident and Beyond (the Summer School). This unique program, in its third year, featured world leaders in nuclear engineering, social science, and history. The student body was comprised of post doctorate researchers and graduate students.

One of the most important questions unanimously raised during this week by the students focused on the professional identity of the nuclear engineer in the post-Fukushima society. Students had difficulty with this, in terms of a real examination of themselves as nuclear engineers and future leaders in the field. This was primarily due to the increasingly complex relationship of nuclear technology with contemporary society. The Fukushima Daiichi accidents resulted in the students coming to realize this relationship in a very real and tangible way. To this end, this chapter will discuss the identity of the nuclear engineer. Specifically, this is directed to what will be termed the 'third generation' engineer; i.e., the student body at the Summer School. In the upcoming decades, it is this 'third generation' that will lead and shape perspectives on nuclear technology and develop new relationships with society. This chapter is intended to pose questions for the nuclear engineer to consider as part of their own, professional self-assessment. This chapter draws primarily from the experiences at the Summer School in an effort to direct meaningful discussions about the need to consider the identity of this third generation nuclear engineer in the post-Fukushima society.

\subsection{Implications of the Fukushima Daiichi Accident to Nuclear Engineering}

The severity of the accidents that occurred at the Fukushima nuclear reactor complex in central-eastern Japan in March 2011 was classified as Level 7 on the International Nuclear and Radiological Event Scale (INES) ${ }^{1}$ by the Ministry of Economy, Trade,

\footnotetext{
1 The INES scale is an internationally accepted tool for communicating the severity of a radiological event. Levels 1-3 represent events that are classified as 'incidents.' Levels 4-7 are defined as 'accidents.' Level 7 specifically is classified as a 'Major Accident.' Three areas of impact are considered in this scale: (1) people and the environment, (2) radiological barriers and control, and (3) defense-in-depth. The scale is logarithmic (similar in concept to the comparative magnitude scale of earthquakes) in that each level represents an accident or incident ten times more severe than the previous level. There are 69 INES Member States.
} 
and Industry ${ }^{2}$ in April 2011 [1, 2]. The Chernobyl accident that occurred in Ukraine (1986) is the only other accident with a Level 7 classification [3]. ${ }^{3}$

These accidents altered the social perceptions of nuclear technology on an unprecedented scale much more so than those at Chernobyl or Three Mile Island. Such strong public response resulted due to the instantaneous access to information and communication on social platforms, such as Twitter. This is an anecdotal judgment based on personal experience and dialogue with participants at the Summer School and many news reports at the time, and not supported by rigorous study. The premise proposed here is that the rapid exchange and availability of information allowed for discussions about the Fukushima Daiichi accidents while events were unfolding in real time, around the world. Based on this, public opinion regarding nuclear engineering issues is historically at its strongest, and this has continued to be the case in the three years following the accident. Contrasting this to the late 1970s-1980s; back then, sources of information were limited to newspapers and the three broadcast television news programs. Today, the 24-h news cycle allows for continuous access to news with a near-infinite amount of resources. ${ }^{4}$

Practical solutions to contemporary problems in the discipline of nuclear engineering are unique and require integration of technical and institutional issues. In this chapter, 'institutional' issues refer to political and societal considerations; those which are primarily in the purview of the social scientists and historians and are not traditionally part of the current nuclear engineering education or professional

2 The Japanese Ministry of Economy Trade and Industry (METI) classified the accident at the Fukushima Daiichi Nuclear Power Station (NPS) as Level 7 on 12 April 2011. METI houses the Nuclear and Industrial Safety Agency (NISA) and Japan Nuclear Energy Safety Organization (JNES). These agencies basically estimated the amount of radioactive materials discharged from the Fukushima Daiichi NPS with additional, separate calculations by Nuclear Safety Commission of Japan (NSC). Both NISA and NSC analyses corresponded to a Level 7 classification on the INES scale.

3 The INES rating for any event is not assigned by a centralized body and therefore is subject to qualitative judgments that inevitably will cause some variation. While both the accidents at Fukushima Daiichi NPS and Chernobyl are classified as Level 7, they should be not considered equivalent. A Level 7 accident indicates implementation of countermeasures to protect the public from the health and environmental effects of radiation. However, this does not mean that these effects have occurred. Additionally, at Chernobyl, twenty-eight reactor staff and emergency workers died from radiation and thermal burns. These deaths are directly attributed to the reactor itself. There have been no deaths at Fukushima Daiichi NPS reported in this way presently. The amount of radioactivity released at Fukushima is only $10 \%$ of the amount released from Chernobyl. Finally, the accident at Fukushima was initiated solely by natural disaster, but the Chernobyl accident resulted due to human factors. These are reported by experts who were in attendance at the Summer School. The severity of the Fukushima accident should not be downplayed by these statements. The ramifications of the accident are serious, both technically and socially. Comparisons between both accidents are expected and have been discussed in mainstream news sources. This technical note is provided for context.

4 See also the uses of social media resulting in the 'Arab Spring,' in 2011, or the 'Green Party' protests in Iran in summer 2010 and 'Discussion on the Fukushima Dai-Ichi Nuclear Power Plant accident' http://www.facebook.com/groups/177355305643452/ as an example of social media in the public dialogue relating to Fukushima. 
training. It is an objective of the Summer School to provide a forum for nuclear engineers to develop some facility with these institutional issues. Additionally, the discipline is also based on a very particular 'historical inertia. ${ }^{5}$ The discipline of nuclear engineering was essentially born during World War II in the form of weapons development. Challenges to nuclear engineering in the public sphere have continued to be affected by this historical inertia; i.e., derived from the legacy of weapons development. Following World War II, nearly a half-century was dedicated to the cold-war arms race against communism. Even with the fall of the Soviet Union, this historical inertia continues; i.e., proliferation risks associated with enrichment of uranium by Iran. When dealing with nuclear reactors, which were developed for peaceful purposes, there is still the risk of plutonium acquisition from used fuel. This historical inertia is always going to be a factor in nuclear engineering problems.

The Fukushima Daiichi accidents also affected current energy policy-making in other nations $[4,5] .6$ This shows a connection of nuclear technology with the public sphere, through institutional issues, and there is little doubt that this will continue. At the Summer School, many questions emerged from the discussion regarding whether nuclear engineers should really operate solely within the technical sphere, separate from that of the institutional and perhaps this was beyond the professional concerns of the nuclear engineer. ${ }^{7}$ In reality, however, a clear demarcation between the technical and institutional will never happen, and, while the nuclear engineer must be a technical expert, they also must develop a facility with institutional issues as well. Frankly, acknowledging this technical and institutional integration is crucial for all nuclear engineers in the post-Fukushima society, and, because of this, the nuclear engineer must be literate in the social sciences and aware of historical inertia. This chapter is focused on how the nuclear engineer can recognize these issues as part of their identity and their place in the discipline in the post-Fukushima society.

\subsection{Goals for This Chapter}

During the Summer School, many discussions involved questions about the identity of the nuclear engineer. In reflecting on the events shortly after the accidents, the student body expressed apprehension at being considered 'nuclear experts' by the public (friends, family, and neighbors). This seemed to be an issue of being perceived as an authority, rather than as just a student or researcher. Many of the

\footnotetext{
5 This 'historical inertia' term was used by Professor Cathryn Carson, UC-Berkeley, Department of History, Office for History of Science and Technology, during discussion on Friday, 05 August, 2011 in order to characterize the inception of nuclear engineering as a discipline.

${ }^{6}$ At the end of May 2011, the Swiss government decided that existing nuclear power plants will close at the end of operating lifetime (2019-2034). Additionally, the coalition German government announced a policy to phase out nuclear power entirely by 2022 .

7 This topic was largely the focus of the student discussion session on Wednesday, 03 August 2011.
} 
participants expressed a lack of preparedness and surprise for this, which was not related to their 'traditional engineering' training. This may be because the prior accidents at Three Mile Island and Chernobyl happened long enough ago that most of the students, who were born in the 1980s, were too young to comprehend implications of the accidents or remember them personally. While learning from those who 'lived through' these accidents at the Summer School is instructive, there is a lack of a certain connection for the student body. The Fukushima Daiichi accidents, however, brought that reality to the forefront for the students. Nearly everyone remarked that this really changed their views on the perception of nuclear engineering in relation to the society.

The goal for this chapter then is to discuss these concerns from the point of view of the "third generation" 8 nuclear engineer. Each generation of nuclear engineer has dealt with many unique challenges and the reasoning in defining the generations proceeds in this way: The first generation of nuclear engineers is those who established the university programs and curricula, at UC-Berkeley, for example, during the 1950s-1960s. Clearly, the societal context was dominated by cold war politics in that nuclear engineering was primarily based on weapons development, the arms race with the Soviet Union, and power reactor development. The second generation, then, would be those currently leading and shaping nuclear engineering research and development who directly studied from the first generation, some of whom participated in the Summer School as lecturers and organizers. While influenced by the cold war, by 1990, this was over, and the arms race essentially ceased. Two major nuclear reactor accidents had essentially ground reactor development in the USA to a halt, and the nuclear engineering community finally began to seriously address the issue of waste disposal.

It follows that the third generation is comprised of the student body at the Summer School, who are those postdoctoral researchers and graduate students, well through their programs of study in nuclear engineering and those who have not yet established permanent careers. During this period of study for the third generation, the so-called nuclear renaissance promised a new era of reactor development. Energy policy has since become more of an energy security concern, as many of the emerging countries are pursuing nuclear power technology. The spread of nuclear technologies to non-weapons states is a societal risk as the potential to produce weapons becomes less technologically prohibitive. European countries have advanced back-end management strategies, while the USA is still trying to develop a repository siting policy, after about 2 decades of research and development at the Yucca Mountain site. Clearly, the challenges in nuclear engineering currently are quite varied and the third generation will be expected to deal with these as leaders in the field over the several decades.

\footnotetext{
${ }^{8}$ Here, the 'third generation' nuclear engineer is not derived based on outside studies. This is an interpretation based on personal experience over about 2 decades of study as a student and researcher in nuclear engineering. There is clearly some overlap between the generations; a socalled 'zeroth generation' could be considered luminaries such as Drs. J. Robert Oppenheimer, Edward Teller, Enrico Fermi et al.
} 
Therefore, this third generation will face challenges in nuclear engineering that are not strictly technically based, and, in the upcoming decades, will lead and shape perspectives, advancements, and education in nuclear engineering. To this end, lessons learned from the Summer School revealed an important question addressing the practical understanding of the nuclear engineering identity: How can the third generation understand that the nuclear engineer is a professional and how can the third generation develop a sense of responsibility related to being a professional? Fundamentally, nuclear engineers must be primarily technical experts. However, a better awareness of the larger context within which the third generation will comport themselves in relation to society requires examination and reflection. Because the topic is very expansive, this chapter will draw upon the experiences directly from the Summer School in an effort to pose a meaningful discussion. ${ }^{9}$

\subsection{Motivation for This Chapter}

The third generation nuclear engineer must recognize that nuclear engineering is a profession that carries certain responsibilities. This was not really recognized by the students during the Summer School. Many students in attendance were asked if they consider nuclear engineering a profession and themselves as professionals. More than half responded in the negative. Furthermore, none were able to recall any specific university studies that were directed to training the nuclear engineer as a professional, nor did contemporaries in the third generation indicate that such issues were routinely discussed. This requires a re-structuring of the engineering university educational system in these terms; clearly, the Summer School is a very worthwhile effort toward this goal, and those organizers who are also faculty members are beginning to make these changes.

The third generation nuclear engineer, though, will most likely enter into the workforce by the time these concepts could be integrated more formally into engineering education. This places a great challenge on them to develop a professional mentality without formal training prior to starting a career in nuclear engineering. There may not be sufficient time to really reflect and learn about nuclear engineering as a profession as there would be afforded in an academic setting. Learning and recognizing the professional role really should start early in the university curricula and not developed ad hoc or 'on the fly.'

\footnotetext{
${ }^{9}$ Clearly, the body of outside scholarship and research based on this topic is tremendous. A thorough investigation concerning the relationship to nuclear engineering to the post-Fukushima society will take several years of serious study, at the least, all of which is necessary and worthwhile. Therefore, fully addressing this in a single chapter is not really possible. By drawing upon the experiences at the Summer School, however, a meaningful dialogue can be initiated for the purposes of self-reflection and examination of the relationship of nuclear engineering to society. It is proposed that the issues addressed in this chapter may motivate the third generation to further consider, study, and reflect on their professional identity, each in different ways.
} 
Observing that Three Mile Island occurred in 1979, Chernobyl in 1986, and Fukushima in 2011, could lead to a pessimistic conclusion that there is risk of a severe nuclear accident nearly every generation. Were another accident to occur in the future, it is the third generation that will be at the forefront of ensuing response. Technical communication with the public in terms of risk management would be an imperative then as it is now. A dialogue addressing the nuclear engineer as a professional, and responsibilities therein, beginning now, could, optimistically, avoid the public problems associated with accidents. Lacking an awareness of the professional concept is a disservice to the public-at-large, and this must be addressed.

\subsection{What Is a Professional?}

A professional is an individual that has experienced some form of rigorous training that involves specialized theory, knowledge, and skills. This is directed for improvement or protection of the society. This usually includes an advanced degree or further training in order to obtain a license to legally practice the given profession. Professional duties are promulgated formally in a code of ethics for the many professions: medicine,${ }^{10}$ law, ${ }^{11}$ and the many disciplines of engineering, including nuclear. ${ }^{12}$ Based on study of these codes of ethics, the professional, generally, is therefore expected to conduct themselves in a manner demonstrating a regard for the public good and an awareness of the societal context within which the profession exists.

Additionally, society itself is becoming increasingly technological, and therefore, the roles of technical experts in terms of protecting public safety are exceedingly crucial. Then, this third generation must recognize that their future role as professionals will include societal considerations. Clearly, this implies that nuclear engineers need significantly more collaboration with others who have professional expertise with institutional issues. This is fairly obvious and not particularly

\footnotetext{
10 The Preamble to the American Medical Association Code of Medical Ethics states (emphasis added): As a member of this profession, a physician must recognize responsibility to patients first and foremost, as well as to society, to other health professionals, and to self.

11 The Preamble and Scope to the American Bar Association Model Rules of Professional Conduct states (emphasis added): Lawyers play a vital role in the preservation of society. The fulfillment of this role requires an understanding by lawyers of their relationship to our legal system. The Rules of Professional Conduct, when properly applied, serve to define that relationship.

12 The Fundamental Principle of the American Nuclear Society states [emphasis added]: ANS members as professionals are dedicated to improving the understanding of nuclear science and technology, appropriate applications, and potential consequences of their use. To that end, ANS members uphold and advance the integrity and honor of their professions by using their knowledge and skill for the enhancement of human welfare and the environment; being honest and impartial; serving with fidelity the public, their employers, and their clients; and striving to continuously improve the competence and prestige of their various professions.
} 
constructive. However, just realizing this is needed advances the profession itself. This includes recognizing that nuclear engineering contains equally important technical and institutional considerations and that these are intertwined. Maintaining more awareness of the context in which the nuclear engineer is working and that relationship to the society is a significant improvement and a realistic near-term goal to the development of the professional third generation nuclear engineer.

\subsection{A Particular Challenge to Engineering as a Profession}

In medicine or law, clients and the professional interact on a personal level. This is largely not the case in engineering because most engineers work for large corporations or national research institutes. Those in academics greatly impact the student body, as educators, mentors, and advisors; however, professional discussions, in and of themselves, in the academic setting are lacking. The engineer's 'client' really is the public-at-large. Nuclear engineers execute computer models that test new reactor designs, build reactor pressure vessels, fabricate nuclear fuel, and work with hazardous chemicals to treat fuels and waste. Nuclear reactor operators are essentially in control of distributing electricity to the nation. There is a lack of experience with direct interaction between the nuclear engineer and the public in all of these. This can contribute to degradation of the professional sense of responsibility. This will impact both present and future society.

This leads to an interesting consideration with respect to the time-scale of nuclear engineering within the concept of the profession. Much of the nuclear engineering profession involves solutions to problems that may not be realized for decades. Current light-water commercial reactors in the world have licenses to operate, initially for forty years, but have been or are in the process of extending lifetimes to 60 years and even greater. The performance assessment for the nuclear waste repository is based on rigorous mathematical modeling that includes nuclear engineering, but also chemistry, materials science, mechanical engineering, and civil engineering. Validation of the performance assessment results cannot be realized for thousands of years at the earliest. Therefore, the 'client' for the nuclear engineer also spans several generations.

Most of the third generation nuclear engineers who are beginning careers now or soon may not have had any opportunity to directly interact with the 'client', and engagement in issues related to the profession may be scant. ${ }^{13}$ Unfortunately, nuclear engineers become severely aware of their clients when an accident like Fukushima occurs and tens of thousands of people are evacuated from their

\footnotetext{
13 Of course, there are those nuclear engineers who are involved in medicine, who will in fact interact with clients individually and directly. However, those nuclear engineers working at a power plant or corporation will affect far more of the public. Lacking a professional sense in this capacity, therefore, is problematic.
} 
homes. This lack of direct interaction is detrimental to the nuclear engineer in terms of really understanding the social responsibility of the profession. If there is a lack of professional responsibility, then can the nuclear engineer truly be serving the public good?

\subsection{Regarding Public Communication as a Form of Professionalism}

Because nuclear engineering is fundamentally based on the integration of the technical with the institutional, and based on interpretation of discussions at the Summer School by the both the third generation and expert lecturers, in terms of professional responsibilities, routine communication with the public by nuclear engineers must be improved. This problem is derived directly from this absence of 'face to face' interaction of the nuclear engineer with the 'client'. In terms of general communication issues, some nuclear engineering topics may be reported in the news, but these are usually when accidents, or potential accidents, occur. This is not a condemnation of the media and reporting practices. Most of the daily news is largely negative in terms of subject matter. Nuclear engineering is one of the subjects that suffers probably more than others, due to historical inertia, in that it is perceived mostly negatively normally. When accidents occur, this usually reinforces the negative public opinion. Conveying accurate information regarding nuclear engineering issues is also very difficult even for those trained in the profession, and further underscores the need for the nuclear engineer to realize that part of the professional responsibility involves public communication.

As an example, based on first-hand observation, in the weeks following the Fukushima Daiichi accident, news crews from ABC, NBC, and CBS frequently interviewed the faculty Department of Nuclear Engineering at UC-Berkeley for technical communication about the accident and related events [6]. However, even this level of communication flows only in one direction, as the nuclear engineer basically just tells the interviewer the state of the subject at hand. This is needed and it is important to do, but a deeper level of public interaction is required, where both the nuclear engineering professional and the public can see one another as both part of the society. Therefore, without regular and direct interaction, or failing to realize that the profession must include some level of this, is an encroachment on professional responsibilities. This is not to place the 'burden of proof' on the public to motivate themselves to hold a more positive attitude regarding nuclear engineering; indeed, this burden is part of the professional responsibility of the third generation nuclear engineer to develop ways that public interaction can be increased.

Meaningful public interaction has been a challenge since the inception of nuclear engineering and drawbacks to this are related to its historical inertia. This has led many times to an 'us versus them' mentality which only fosters antagonism. This has historically shown to be the wrong approach. This can occur when 
so-called 'technocrats,' while well intentioned, try to make decisions based solely on science and engineering by relying on a responsibility for 'good of the public,' without experiencing or communicating directly with the public, whom these decisions affect. Generally, most repository siting issues are examples of this. In the case of low-level waste repository siting in South Korea, technocrats with a strong voice in the federal government attempted to unilaterally establish a waste site and were met with strong public opposition at sites around the country for nearly two decades. ${ }^{14}$ Separation of the nuclear engineer from the public leads to an adoption of a paternalistic attitude. Rather, the nuclear engineer must understand that they are in fact part of the public that they purport serve. Because of this, technical communication should be developed in a more inclusive manner. This task is still rather difficult, but a more evolved approach to public communication should be considered within the responsibility of the nuclear engineering professional.

\subsection{Beginning to Understand Professional Ethics as a Responsibility}

Building on the premise that engineers must recognize themselves as part of the society, it becomes clear that engineering solutions have some functional relationship with the society. This can be attained by realizing that the professional engineer is an ethical engineer. The third generation must develop this self-awareness. How then can the connection between professional responsibilities and professional ethics be recognized?

Developing professional ethics is a continual process. This can be defined as the design of conduct in engineering practice. ${ }^{15}$ Professional ethics can only really be developed by the nuclear engineer with time. This topic is very broad ranging and there are many different ethical approaches that can be considered based on realistic, personal experiences of each nuclear engineer. However, self-awareness of an ethical responsibility at the start of professional development could prove instructive.

To start, for the third generation, a critical aspect of developing an ethical point of view, as a professional nuclear engineer, is culture. This is becoming very important as the world becomes smaller, and therefore more interrelated and complex. Consideration of ethics in engineering is essential for all engineers themselves in order to work in and be a part of the global community. This goes beyond simply reading the codes of ethics provided by the professional society. The third generation of nuclear engineer needs to consider a new definition of what it means to be professional which will include ethics. Codes of ethics can serve as an interface between the profession and expectations for the public, but these are

14 Although, it should be noted that there is still a political factor to these issues.

15 This is a formal definition provided by experts in the field at the Summer School. 
constrained. They are based on universal principles of morality, which is needed, but lack context. This is where cultural understanding is critical. This requires not only honest communication, but also a combination of honesty and sincerity. This will be essential in establishing a new professional outlook.

From a micro-ethics perspective, the third generation can consider their individual research or professional goals in terms of responsibility to society. This perspective was alluded to in the Summer School discussions in that in the immediate events after the accident the student body had concerns about their appropriate individual response to the public concerning the accidents. The macro-level perspective can also be addressed at this stage of professional development for the third generation as well, as the Summer School was clearly designed as a forum to discuss the role of nuclear engineering and engineers within the society. This macro-level also may be the most important viewpoint that requires serious thought and change by all engineers in the post-Fukushima society, but especially by the third generation, in that relationships with the public are still nascent and are not encumbered by prior experience, whether positive or negative. Part of the goal of this chapter is to address the need for an understanding that nuclear engineering itself is a profession with related and defined responsibilities; this is a meso-level ethical understanding. The meta-level of ethical understanding may not yet be achievable as the third generation, as this seems to require some hindsight that is developed with professional experience, though, at the least, being receptive to questioning the nature of engineering could be a constructive development moving forward from Fukushima.

Additionally, in terms of ethical considerations and societal context as part of the professional responsibilities, there were many conversations at the Summer School that focused on premises such as, 'We need to convince the public of the benefits of nuclear power' or 'we have to show what the risks really are.' However, it was strongly implied and at times outright stated that if the public does not agree with such benefits, then they are 'wrong' and 'acting irrationally.' This direction of thought is a misguided form of communication and does not serve the public. This is professionally unethical in that there is a failure to comprehend the societal context in which the 'benefits' are proposed.

Engineering is fundamentally based on a logical reasoning. The dominant paradigm in engineering of any discipline is utilitarianism; i.e., the probabilistic risk assessment or cost/benefit analysis. While these do contain some degree of subjective judgment, overall, they are overwhelmingly mathematically and logically based. However, to expect the engineer to conduct himself or herself professionally strictly by logic would be misguided. This is again a problem with the separative and erroneous concept of 'engineers' and 'the public,' in that this leads to a tendency, also observed at the Summer School, with engineers that thinking strictly in logical terms will lead to the only 'correct answer.' The 'correctness' of any answer is determined by the functional relationship with engineering as part of the public sphere.

For example, the risks and benefits of nuclear power in Germany, Switzerland, or the USA really did not change after the Fukushima accidents; however, the 
societal context for this certainly did change, and the question as to whether nuclear power should be discontinued is not strictly dependent on engineering solutions in any nation. In Germany and Switzerland nuclear power will be phased out, but in the USA current policies will be maintained. This is not to imply that engineering solutions are without merit. Probabilistic risk assessments must be conducted in order to determine whether if such measures as backfitting, etc., will reduce risks at any power plants. This is being done in response to the accidents in many nations, including the USA. Ultimately, if these risks can be reduced significantly, this does not mean that if a nation elects not to continue nuclear power development that this is the 'wrong' decision. The consequences of the accident, emotionally or monetarily, may be too great for the society to bear. ${ }^{16}$

To consider that all of these issues can be 'correctly' determined by purely logical means, is professionally unethical. Frankly, it is nonsensical that anyone should be expected to act strictly in a logical manner, devoid of emotion [7]. ${ }^{17}$ This overemphasis on logic contributes to the lack of understanding about the relationship between nuclear engineering and society; real, practical solutions just cannot be attained in this way. The nuclear engineer must recognize his or her own relationship within the society in order to perceive the larger, functional relationship of engineering with the society. This can potentially be achieved by considering their own value systems and working to apply these to the precepts of the profession, i.e., for the public good, as well as the values of the society within which they are also members themselves.

\subsection{Final Remarks Regarding Nuclear Engineering as a Profession}

Contemporary challenges to nuclear engineering, as a profession, will be affected by historical inertia. Much of the public currently would think of a bomb first, when prompted to remark about nuclear engineering topics. This is not an unreasonable public reaction; the proliferation of nuclear technology in this way is still problematic. More and more nations seek access to nuclear technology for energyproducing purposes and this presents a growing security and proliferation risk regarding the use of nuclear technology for nefarious purposes.

\footnotetext{
16 This of course raises the issue of alternative energy sources, which can be also debated at length, but the main point is that none of these decisions can be made without considering the society.

${ }^{17}$ Even the epitome of the rational individual, the singular Mr. Spock, expressed outright joy when he realized that he did not kill Captain Kirk during the kal-if-fee (Amok Time, TOS\#30). The myth of the engineer, that individual, acting in a strict logical manner, devoid of emotion, and arriving at a single 'correct answer,' is itself, highly illogical. Extensive scholarly endeavors are currently devoted to the subject of emotions in engineering and the manner in which professional ethics can be developed in this way. While not specifically discussed at the Summer School, further contemplation of this may be a good start for the developing identity for the third generation nuclear engineer.
} 
Nuclear engineering, as a profession, is also challenging because although the profession is technically based, the professional cannot reside strictly in this technical arena. In understanding nuclear engineering as a profession, the third generation must grasp that technical approaches are necessary, but not sufficient, and that both social science literacy and professional ethics development are required to achieve solutions to contemporary nuclear engineering problems with any modicum of practicality. A social and political awareness will always frame nuclear engineering issues and this must be internalized as part of an inherent sense of professional responsibility. This may not be fully achievable currently, but if the third generation can begin to think about the profession with a more expansive scope, then their role can grow stronger, professionally. Research and technological development alone does not solely support and extend the goals of the profession in relation to society, without collaboration with the society.

Open Access This chapter is distributed under the terms of the Creative Commons Attribution Noncommercial License, which permits any noncommercial use, distribution, and reproduction in any medium, provided the original author(s) and source are credited.

\section{References}

1. International Atomic Energy Agency (2009) INES: The international nuclear and radiological event scale user's manual. Vienna, Austria

2. Government of Japan, Ministry of Economy, Trade, and Industry (12 April 2011) News release

3. Nuclear Energy Institute (2011) Nuclear energy insight. Washington, D. C.

4. BBC News (25 May 2011) Swiss to phase out nuclear power

5. BBC News (30 May 2011) Germany: Nuclear power plants to close by 2022

6. ABC news (17 March 2011) Other options to help Japan's nuclear crisis?

7. Roeser S (2012) Emotional engineers: Toward morally responsible design. Science and Engineering Ethics 18:103-115 